\title{
Imaging and analysis of genetically encoded calcium indicators linking neural circuits and behaviors
}

\author{
Jihae Oh", Chiwoo Lee", and Bong-Kiun Kaang* \\ School of Biological Sciences, Seoul National University, Seoul 08826, Korea
}

\section{ARTICLE INFO}

Received January 14, 2019

Revised May 29, 2019

Accepted May 29, 2019

*Correspondence

Bong-Kiun Kaang

E-mail: kaang@snu.ac.kr

\section{Key Words}

Calcium channel

Calcium imaging

Data analysis

Miniscope

Neuronal calcium-sensor proteins

\#These authors contributed equally to this work.

\begin{abstract}
Confirming the direct link between neural circuit activity and animal behavior has been a principal aim of neuroscience. The genetically encoded calcium indicator $(\mathrm{GECl})$, which binds to calcium ions and emits fluorescence visualizing intracellular calcium concentration, enables detection of in vivo neuronal firing activity. Various GECls have been developed and can be chosen for diverse purposes. These GECl-based signals can be acquired by several tools including two-photon microscopy and microendoscopy for precise or wide imaging at cellular to synaptic levels. In addition, the images from $\mathrm{GECl}$ signals can be analyzed with open source codes including constrained non-negative matrix factorization for endoscopy data (CNMF_E) and miniscope 1-photon-based calcium imaging signal extraction pipeline (MIN1PIPE), and considering parameters of the imaged brain regions (e.g., diameter or shape of soma or the resolution of recorded images), the real-time activity of each cell can be acquired and linked with animal behaviors. As a result, GECI signal analysis can be a powerful tool for revealing the functions of neuronal circuits related to specific behaviors.
\end{abstract}

\section{INTRODUCTION}

A major goal of modern neuroscience is to detect the neural firing patterns linking circuit dynamics to behaviors. For many decades, genetically encoded fluorescent protein down-stream of IEG promoters (e.g., c-fos, Arc, Egrl, and Homerla), usually through virus injecting methods, or immunochemistry detecting the same IEG proteins, were used to label neuronal cells that fired during a specific behavior [1-7]. However, these indirect approaches have a critical limitation - there cannot be accurate evidence of neuronal cell firing during a behavior because the role and precise mechanism of IEG expression is unknown and the induction protocol is imperfectly regulated, even though many researchers have used these methods for evidence of cell firing during specific behaviors [8-12]. Along with these reasons, to understand the operational principles of neural circuit dynamics, the order of connectivity should be considered. Neural circuits consist of series of connections-chains coupling presynaptic to postsynaptic neurons corresponding to firing order. Therefore, the order of firing pattern is essential, and the time point of firing for each cell should be considered to understand the operational fashion of neural circuits.

For these reasons, recent neuroscience research trends have utilized cell-type specific and low-level circuit studies [13-19] as well as tracking dynamics of functional ensembles at single cell resolution in real-time [20,21]. Genetically encoded ion indicators developed for recording electrochemical events of the action potential can be applied to both research types. Many studies for specific cell-type or circuit already exist; however, to collect more convincing evidence of direct neural activities that represent the real world, a direct method to detect cells firing simultaneously with an animal behavior is rising and needed. During the last 
two decades, much effort has focused on capturing 'real-time' cell activities by recording electrochemical events, and several techniques have been developed based on the action potential principle. As a result, major ions $\mathrm{Na}^{+}, \mathrm{K}^{+}$, and $\mathrm{Ca}^{2+}$ of membrane potential have become powerful candidates for developing optical indicators-by expressing a fluorescent ion indicator under a specific promoter, the real-time single cell activities of targeted ensembles can be visualized.

In this review, we discuss the developmental history as well as the pros and cons of ion indicators, focusing on genetically encoded calcium indicators (GECIs). Along with GECI properties, we discuss the imaging methods and corresponding GECI signal analysis. This review aims to offer an overview of the biophysical properties and limitations of the different GECI variants and to provide perspective to GECI users for choosing the best-suited variants.

\section{WHY GECI?}

To detect neuronal activities, two targets are accessible: voltage and ions. One possible way is to identify the voltage dynamics when cells undergo a series of action potential phases-the depolarization, repolarization, hyperpolarization, and resting phases. For this purpose, genetically encoded voltage indicators (GEVIs) have been developed. GEVIs are fusions of a four-pass voltagesensing domain (VSD) and fluorescent proteins [22-25]. A conformational change of the VSD modulates the brightness of the fluorescent protein [26]. GEVIs can detect hyperpolarization and subthreshold depolarizations and have faster kinetics than GECIs [27]. Although there are several advantages of using GEVIs, localizing them to the plasma membrane has been difficult; poor GEVI targeting to the plasma membrane is the main reason for the lag behind GEVI development compared to that for GECIs $[28,29]$. Despite these challenges, there are several GEVIs currently being used, such as ASAP2f and ArcLight [30,31].

Alternatively, neuronal activities can be detected via ion dynamics. Ions associated with the electrochemical event of an action potential represent the precise dynamics of internal and external concentrations. Several ion probes have been developed-sodium binding fluorescent indicators (SBFIs), potassium binding fluorescent indicator (PBFIs), and calcium indicators that detect $\mathrm{Na}^{+}, \mathrm{K}^{+}$, and $\mathrm{Ca}^{2+}$ ions, respectively. PBFIs are not proper indicators for cell activity. Potassium ions are already abundant in intracellular spaces and are released after sodium influx, making researchers trace the slow signal dissolution. Indeed, for detecting the firing of neuronal cells, we should focus on the ions that induce membrane depolarization. For these reasons, potassium indicators are not suitable for representing neuronal activities. In the case of sodium indicators, most types are chemical SBFIs, such as CoroNa Green (or Red), Asante NaTRIUM Green2 (ANG-2), and $\mathrm{Na}^{+}$-binding benzofuran isophthalate (SBFI-AM) [32]. These chemical sodium indicators should be delivered to cells via a micropipette, which is the main limitation for in vivo experimental application. A few genetically encoded indicators have been developed that are based on sodium channel proteinbased activity reporting constructs (SPARCs) $[24,33]$. Although SPARCs report the gating of the sodium channel with fast kinetics ( $2 \mathrm{~ms}$ ), SPARCs cannot provide information about the sodium ion concentration per se because they are composed by inserting green fluorescent protein (GFP) sequence into the rat $\mu \mathrm{I}$ skeletal muscle sodium channel sequence, limiting their application [24]. Above all, sodium has a high basal intracellular concentration and a small activity-driven concentration gap between extraand intra-cellular concentrations (Table 1) [34,35], increasing the potential for noise. This demerit can be managed with data postprocessing; however, in the case of in vivo neuronal recording, in which many cells are piled up along $\mathrm{z}$-stack, it becomes more difficult to overcome the small signal-to-noise gap.

Compared to sodium ions, calcium ions are more attractive targets. The low basal calcium concentration state enables minimizing nonspecific background signal, and the concentration gap between the basal and activated states is considerably more significant for calcium than sodium (Table 1). Additionally, calcium ion influx is the first step of neuronal activation, with fast action potential and decaying time dynamics. Most of all, as an optical indicator, calcium indicators can provide information on calcium dynamics that electrophysiological recording and functional magnetic resonance imaging cannot.

Exploiting these calcium ion properties, several kinds of calcium dyes have been developed; there are two main categories: (1) chemical calcium dyes and (2) GECIs. In the early days, chemical calcium dyes were first developed, such as fluo-4 or Oregon Green BAPTA (OGB)-1; however, these kinds of chemical dyes are delivered via cell permeabilization by a whole-cell patchclamp or with an acute bulk loading protocol under lipophilic

Table 1. Ion concentrations

\begin{tabular}{ccccc}
\hline Ion & $\begin{array}{c}\text { Resting state } \\
\text { concentration }(\mathrm{mM})(\mathrm{a})\end{array}$ & $\begin{array}{c}\text { Activated state } \\
\text { concentration }(\mathrm{mM})(\mathrm{b})\end{array}$ & $\begin{array}{c}\text { Activity-driven } \\
\text { concentration gap (b/a) }\end{array}$ & $\begin{array}{c}\text { Membrane permeability } \\
\text { at rest }\end{array}$ \\
\hline $\mathrm{Na}^{+}$ & 10 & 55 & 5.5 & 0.05 \\
$\mathrm{~K}^{+}$ & 96 & 94 & 0.98 & 1 \\
$\mathrm{Ca}^{2+}$ & $0.05-0.1$ & $0.7-1$ & $7-20$ & 0 \\
\hline
\end{tabular}


conditions that can damage cells and constrain subsequent imaging conditions [36,37]. In contrast, GECIs are noninvasive and are easily expressed through virus-delivery methods, such as adenoassociated virus or lentivirus, with the least damage. In addition, GECIs allow for selective yet unbiased labeling of neuronal cell types or populations, such as those comprising an engram [21]. This enables research on the firing pattern of each neuronal cell type as well as ensembles of neuronal events.

Despite many pros, GECIs also have limitations. Since most GECIs are based on the $\mathrm{Ca}^{2+}$-binding mechanism of calmodulin and calmodulin-binding proteins, the $\mathrm{Ca}^{2+}$ chelating phenomena can occur; $\mathrm{Ca}^{2+}$ chelating can provoke interference with intracellular signaling pathways or several calcium channels, though there are instances in which GECIs do not interrupt the function and development of voltage-gated $\mathrm{Ca}^{2+}$ channels (VGCCs) [38]. Hence, virus titer conditions are critical to proper GECI expression.

\section{CALCIUM DYNAMICS}

For proper analyzing and representing neuronal activities with
GECI signals, understanding how calcium concentration changes in neurons is essential. Calcium ions are involved in multiple functions including muscle contraction, hormone secretion, and intracellular metabolism, which occur over a wide temporal range in the body-from microseconds to hours [39]. Among the properties of $\mathrm{Ca}^{2+}$ ions, time courses, amplitudes, and related sub-compartment activity are regarded as important biological factors. Furthermore, calcium ions perform unique roles in the nervous system including promoting neurotransmitter release by inducing synaptic vesicle exocytosis; accordingly, calcium ion concentration is important in determining synaptic plasticity at synaptic ends. Most neurons have calcium concentrations of 50 to $100 \mathrm{nM}$, which raises tens of times during an action potential [40].

There are some well-known calcium sources related to intracellular calcium dynamics (Fig. 1). Extracellular space is the primary source of calcium ions that interact with neurons via plasma membrane receptors and ion channels. There are three major groups of calcium channels in the plasma membrane: (1) VGCCs, (2) receptor-operated $\mathrm{Ca}^{2+}$ channels (ROCs), and storeoperated $\mathrm{Ca}^{2+}$ channels (SOCs). VGCCs mainly respond to electrical signals induced by calcium ion binding [41]; especially in neurons, the VGCC works as an impulse generator or propagator

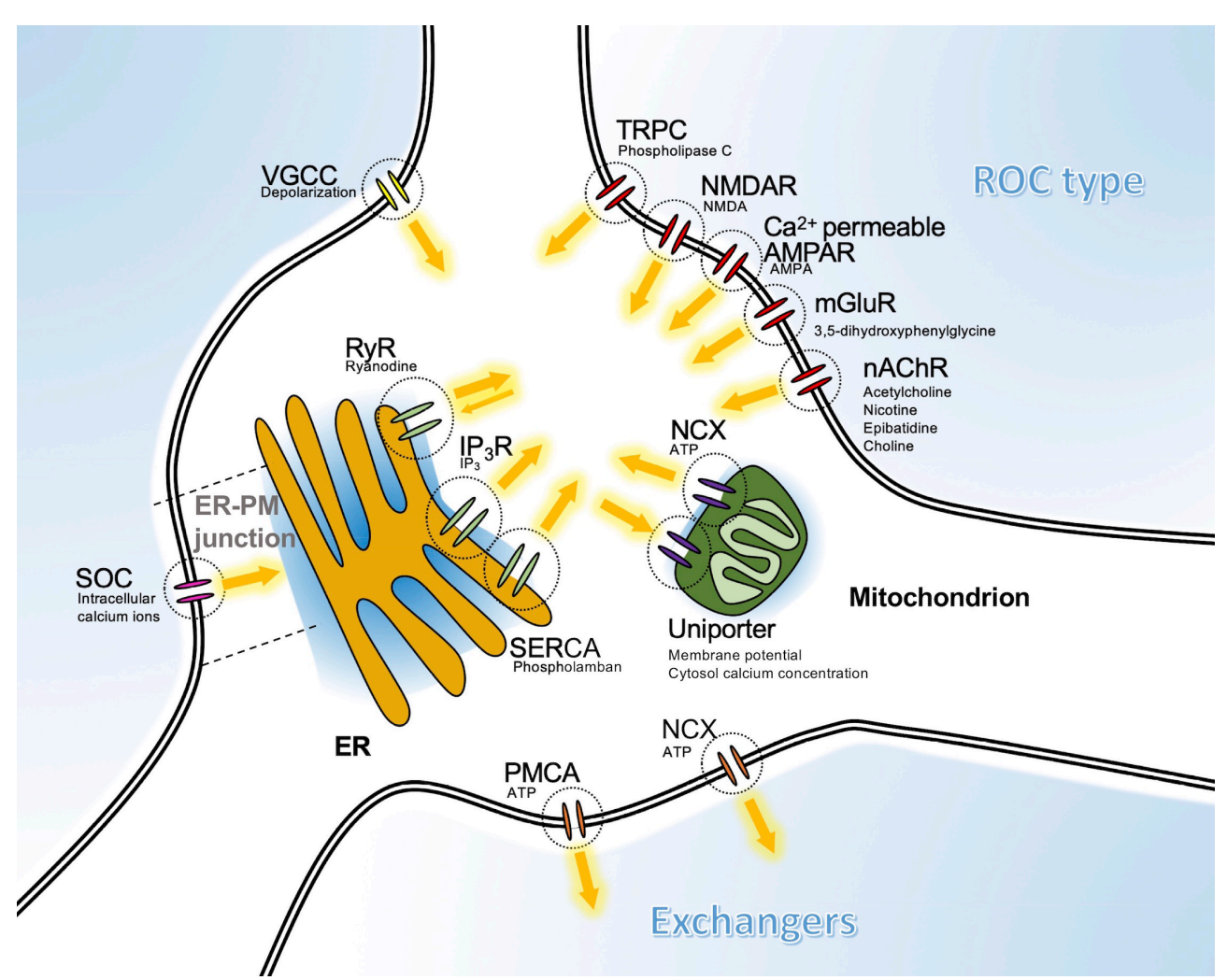

Fig. 1. Neuronal calcium signaling. Voltage-gated calcium channels (VGCCs), N-methyl-D-aspartate glutamate-type receptors (NMDARs), calciumpermeable alpha-amino-3-hydroxy-5-methyl-4-isoxazolepropionic acid receptors (AMPARs), metabotropic glutamate receptors (mGluRs), storeoperated channels (SOCs), transient receptor potential type C (TRPC) channels, and nicotinic acetylcholine receptors (nAChRs) are sources of calcium influx. Ryanodine receptors (RyRs) and inositol trisphosphate receptors $\left(\mathrm{IP}_{3} \mathrm{Rs}\right)$ mediate the calcium release from internal stores. The sarco-/endoplasmic- reticulum calcium ATPase (SERCA), plasma membrane calcium ATPase (PMCA), and sodium-calcium exchanger (NCX) mediate calcium efflux. $\mathrm{ROC}$, receptor-operated $\mathrm{Ca}^{2+}$ channel. Additionally, mitochondria are important for neuronal calcium homeostasis. 
that consist of several subunits; $\alpha 1, \alpha 2 \delta, \beta$, and y [42]. Unlike VGCCs, ROCs are activated by the binding of specific ligands including excitatory neurotransmitters, such as L-glutamate. Two types of receptors are classified as ROCs-metabotropic receptors (mGluRs) and ionotropic receptors (iGluRs) including alphaamino-3-hydroxy-5-methyl-4-isoxazole propionic acid-sensitive receptors (AMPARs) and $\mathrm{N}$-methyl-D-aspartate sensitive receptors (NMDARs) in neurons and glial cells [43]. The SOC is a recently found structure [44] and is activated by STIM proteins accumulated at endoplasmic reticulum (ER) and plasma membrane (PM) junctions through the depletion of $\mathrm{Ca}^{2+}$ from the ER. Calcium influx through SOCs increases local calcium concentration and initiates signaling pathways including gene transcription and secretion [44]. Regarding calcium channels, exchanger types also exist; both the plasma membrane $\mathrm{Ca}^{2+}$ ATPase (PMCA) and $\mathrm{Na}^{+} / \mathrm{Ca}^{2+}$ exchanger (NCX) play roles in cellular calcium export. PMCA has a high $\mathrm{Ca}^{2+}$ affinity but less capacity for transport, whereas NCX works in the opposite way [45].

Cell organelles are the second major source of calcium ions. The endoplasmic reticulum releases calcium ions through two types of ion channels/receptors: ryanodine receptors (RyRs) and inositol-1,4,5-trisphosphate receptors $\left(\mathrm{IP}_{3} \mathrm{Rs}\right)$. RyRs tend to be expressed in neuronal and muscular cells and are activated when intracellular calcium concentrations increase [46], while the $\mathrm{IP}_{3} \mathrm{R}$ pathway is mostly controlled by neurotransmitters [47]. Mitochondria play a significant role in the regulation of calcium signaling, accumulating calcium ions in the mitochondrial ma- trix through the buffering of calcium ions and connecting with adjacent ER channels. This calcium ion accumulation contributes to ATP production used for feedback regulation of the mitochondrial calcium channel [48].

In addition to direct calcium sources, calcium-binding proteins-calcium buffers and calcium sensors-also affect intracellular calcium concentration by regulating calcium ion availability [49]. Hence, the calcium ions themselves can play roles as essential factors regulating both the RyR and $\mathrm{IP}_{3} \mathrm{R}$ pathways, which comprise internal feedback loops that lead to dendritic calcium waves in neocortical and other neuronal types [50]. Furthermore, an action potential in neurons could induce calcium influx and, consequently, RyR-mediated processes in the ER [51].

\section{GECI DEVELOPMENT}

Developing calcium sensors is one of the main branches in the improvement of calcium imaging systems. The initial calcium indicators for observing calcium dynamics at the cellular level were aequorin [52] and arsenazo III [53]. When combined with calcium ions, these indicators emit light of a specific wavelength or change absorption spectrum. However, because of their lower sensitivity to calcium ions and a short range of detectable calcium concentration, chemical calcium indicators, such as fluo-4 [54], are beginning to be developed using calcium-selective chelators that generate more accurate calcium signals. Chemical calcium

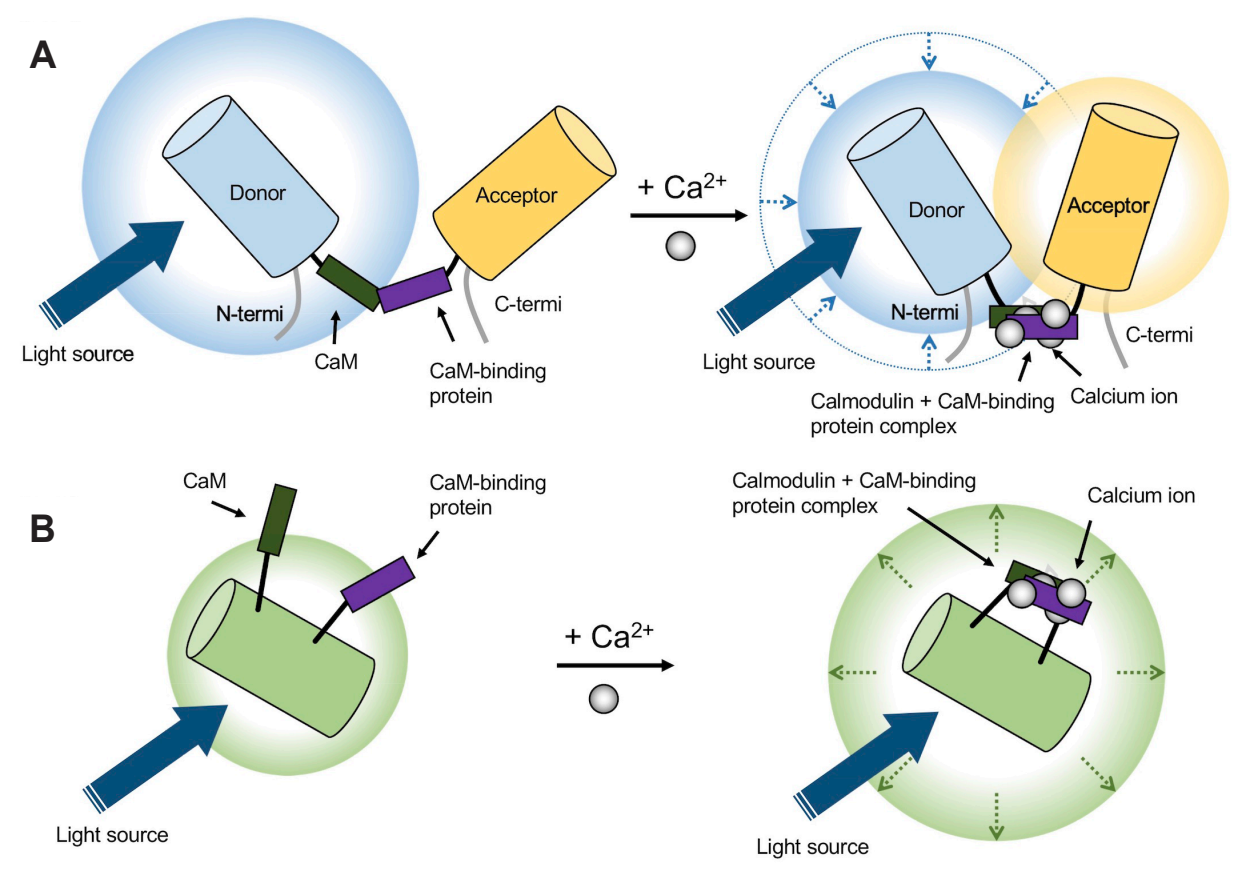

Fig. 2. Genetically encoded calcium indicators (GECI). (A) Fluorescence resonance energy transfer (FRET)-based GECl. Calcium ion binding enables approaching of donor with acceptor to induce FRET. (B) Single-fluorophore GECl. Calcium ions bind to an indicator that causes conformational changes leading to an increase of emitted light at fluorescence wavelengths. CaM, calmodulin; termi, terminal. 
indicators have been used widely in the neuroscience field, because of their broader excitation spectra and higher calcium affinity. Additionally, accompanied by the popularization of viral delivery methods, GECIs, named cameleons [55], were introduced with calcium binding domains cloned from a living organism and could be used for cell type-specific studies. GECIs rapidly have

Table 2. Frequently addressed GECl properties

\begin{tabular}{|c|c|c|c|c|c|c|c|c|c|}
\hline Category & Sub-category & Indicator & $\mathrm{Em}(\mathrm{nm})$ & $\mathrm{D}$ & $\mathrm{n}$ & $\mathrm{pK}_{\mathrm{a}}$ & $\mathrm{K}_{\mathrm{D}}(\mu \mathrm{M})$ & $\tau_{\mathrm{rt}}(\mathrm{ms})$ & Reference \\
\hline \multirow{19}{*}{$\begin{array}{l}\text { Two- } \\
\text { fluorophore }\end{array}$} & \multirow[t]{15}{*}{ Cameleons } & YC2.0 & $480(530)$ & $\sim 1.8$ & & & & 83 & 55,63 \\
\hline & & YC2.1 & $476(528)$ & $\sim 2$ & $1.8 / 0.6$ & & $0.1 / 4.3$ & $350 / 3,070$ & 74 \\
\hline & & YC2.6 & $480(530)$ & 6.6 & $2.7 / 1.0$ & & $0.09 / 0.95$ & & 75 \\
\hline & & YC3.1 & 476 (528) & $\sim 2$ & 1.1 & & 1.5 & & 74 \\
\hline & & YC3.6 & $480(530)$ & 6.6 & $1.7 \mid 3.6 / 1.2$ & & $0.25 \mid 0.22 / 0.78$ & 2,940 & 75 \\
\hline & & YC4.6 & $480(530)$ & 4.6 & $1.7 / 0.9$ & & $0.06 / 14.4$ & & 75 \\
\hline & & YC-Nano140 & $480(530)$ & 14.0 & $2.0 / 0.9$ & & $0.14 / 0.75$ & 3,030 & 76 \\
\hline & & YC-Nano65 & $480(530)$ & 14.0 & 1.6/1.8 & & $0.06 / 1.4$ & & 76 \\
\hline & & YC-Nano50 & $480(530)$ & 13.5 & $2.5 / 1.0$ & & $0.05 / 0.4$ & & 76 \\
\hline & & YC-Nano30 & $480(530)$ & 13.5 & $2.4 / 1.3$ & & $0.03 / 0.2$ & & 76 \\
\hline & & YC-Nano15 & $480(530)$ & 15.5 & $3.1 / 0.6$ & & $0.016 / 0.3$ & & 76 \\
\hline & & D1 & $480(535)$ & & & & $0.81 / 60$ & & 77 \\
\hline & & $\mathrm{D} 2 \mathrm{cpV}$ & $480(535)$ & 5.3 & & & $0.03 / 3.0$ & & 77 \\
\hline & & D3cpV & $480(535)$ & 5.1 & & & 0.6 & & 77 \\
\hline & & D4cpV & $480(535)$ & 3.8 & & & 64 & & 77 \\
\hline & \multirow[t]{3}{*}{$\mathrm{TNs}$} & TN-L15 & $480(535)$ & 2.4 & 1.0 & & 1.2 & 1,330 & 63,78 \\
\hline & & $\mathrm{TN}-\mathrm{XL}$ & $480(535)$ & 5.0 & 1.7 & & 2.5 & 240 & 63,79 \\
\hline & & $\mathrm{TN}-\mathrm{XXL}$ & $480(535)$ & 3.3 & 1.5 & & 0.8 & 620 & 79 \\
\hline & Etc. & D1GO-Cam & $510(560)$ & & & & 1.53 & & 80 \\
\hline \multirow{27}{*}{$\begin{array}{l}\text { Single- } \\
\text { fluorophore }\end{array}$} & \multirow{12}{*}{ GCaMPs } & GCaMP1.3 & 510 & 4.5 & 3.3 & & 0.24 & 330 & 62,63 \\
\hline & & GCaMP1.6 & 510 & 5 & 3.8 & & 0.15 & 260 & 63,64 \\
\hline & & GCaMP2 & 511 & 5 & 3.8 & $8.7 / 7$ & 0.15 & & 56 \\
\hline & & GCaMP3 & 513 & 12.3 & 2.1 & $8.4 / 7$ & 0.33 & 700 & $65-67$ \\
\hline & & GCaMP5A & 510 & 17.4 & 2.7 & $8.7 / 6.8$ & 0.31 & & 66 \\
\hline & & GCaMP5D & 510 & 22 & 2.5 & $8.9 / 7.4$ & 0.73 & & 66 \\
\hline & & GCaMP5G & 510 & 32.7 & 2.5 & $9.1 / 7$ & 0.46 & & 66 \\
\hline & & GCaMP5K & 510 & 9.4 & 3.8 & & 0.19 & & 66 \\
\hline & & GCaMP5L & 510 & 17.7 & & & 0.39 & & 66 \\
\hline & & GCaMP6f & 510 & 51.8 & 2.2 & $8.8 / 6.3$ & 0.38 & & 68 \\
\hline & & GCaMP6m & 510 & 38.1 & 3.0 & $8.7 / 6.9$ & 0.17 & & 68,69 \\
\hline & & GCaMP6s & 510 & 63.2 & 2.9 & $9.8 / 6.2$ & 0.14 & & 68 \\
\hline & \multirow[t]{8}{*}{ GECOs } & G-GECO1 & 512 & 25 & 2.7 & 10/7.6 & 0.75 & 700 & 65 \\
\hline & & G-GECO1.1 & 512 & 27 & 2.6 & $10.2 / 7.5$ & 0.62 & 700 & 65 \\
\hline & & G-GECO1.2 & 513 & 24 & 3.0 & $10.4 / 7.2$ & 1.15 & 700 & 65 \\
\hline & & B-GECO1 & 446 & 8 & 2.0 & $5.0 / 5.6$ & 0.16 & 490 & 65 \\
\hline & & R-GECO1 & $600 / 589$ & 17 & 1.6 & $8.9 / 6.6$ & 0.48 & 752 & 65 \\
\hline & & GEX-GECO1 & $512 / 506$ & 27 & 2.0 & 6 & 0.32 & 1,030 & 65 \\
\hline & & GEM-GECO1 & $511 / 455$ & 111 & 2.0 & 6.2 & 0.34 & 224 & 65 \\
\hline & & jRGECO1a & 630 & 11.6 & 1.9 & $8.6 / 6.3$ & 0.15 & & 70 \\
\hline & \multirow[t]{3}{*}{ Pericams } & F-Pericam & 514 & 8 & 0.7 & & 0.7 & & 71 \\
\hline & & I-Pericam & $515 / 517$ & 6.7 & 1.0 & & 0.2 & 940 & 71 \\
\hline & & R-Pericam & $511 / 517$ & 10 & 1.1 & & 1.7 & & 71 \\
\hline & \multirow[t]{2}{*}{ Camgaroos } & Camgaroo-1 & $\sim 513$ & 7 & 1.6 & $10.1 / 8.9$ & 7.0 & & 72 \\
\hline & & Camgaroo-2 & 535 & 7 & 1.2 & & 5.3 & & 73 \\
\hline & CatchER & CatchER & 510 & 1.8 & 0.94 & 6.9 & 180 & 1.5 & 58 \\
\hline & Etc. & RCaMP1h & 630 & 12.6 & 2.2 & & 7.1/5.7 & & 70 \\
\hline
\end{tabular}

$\mathrm{GECl}$, genetically encoded calcium indicator; GECO, genetically encoded calcium indicators for optical imaging; Em, emission wavelength; D, dynamic range; $\mathrm{n}$, Hill constant, which is related to the steepness of the fluorescence change of indicator [61]; $\mathrm{pK}_{\mathrm{a}}$ acidity constant $\left(20^{\circ} \mathrm{C}-25^{\circ} \mathrm{C}\right) ; \mathrm{K}_{\mathrm{D}}$, dissociation constant; $\tau_{\mathrm{rt}}$, time constant of the dissociation reaction $\left(20^{\circ} \mathrm{C}-25^{\circ} \mathrm{C}\right)$. When $\tau$ is not specified in the reference, it is calculated from $\tau=\Theta / k_{\text {off' }}$ assuming $\Theta=1$ [61]. A vertical bar ' $\mid$ ' is used for values from different references, calcium depleted/saturated condition, and slash ' $\%$ is used for the calcium depleted/saturated condition $\left(\mathrm{Em} \mathrm{pK} \mathrm{p}_{\mathrm{a}}\right)$ or from two-component fittings $\left(K_{D}, n, \tau_{r t}\right)$. The table includes data from Mank and Griesbeck [82]. 
overcome issues of previous indicators including slow responses and low signal-to-noise ratios. GECIs have become promising indicators because they can be genetically modified for studying living organisms in optimum biological conditions [56].

Generally, GECI design consists of three components: calmodulin (CaM), a CaM-binding domain (e.g., M13 and RS20), and a circularly permuted green fluorescent protein (cpGFP) or enhanced cpGFP (cpEGFP). Calmodulin has four calcium binding $\mathrm{EF}$ hands that can induce conformational changes of GECIs that makes a tight ring around the CaM-binding domain. Subsequently, this calmodulin-CaM-binding protein complex creates a new domain interface that combines with cpGFP or cpEGFP [57]. These moieties can be modified to improve the proper fluorescent signal, such as with CatchER [58].

In principle, GECIs can be classified into two types: (1) fluorescence resonance energy transfer (FRET)-based and (2) singlefluorophore-based (Fig. 2). The FRET types are a combined form of two fluorescent proteins. When calcium ions are attached, the distance between the two proteins decreases ( $<10 \mathrm{~nm}$ ), inducing non-radioactively energy transfer between donor and acceptor fluorophores [59]; therefore, FRET changes both fluorophores' light emission properties, which depends on the ratio of donors to acceptors. Single-fluorophore GECIs show conformational changes mostly through CaM and cpGFP/cpEGFP. This induces chromophore deprotonation, like phenolate oxygen, that leads to an increase in fluorescent emission [57,60]. The GCaMP family is a well-known single-fluorophore GECI.

For deliberate indication of biological calcium activities, some essential GECI features should be considered including, but not limited to, dynamic range, signal-to-noise ratio, ion affinity, ion selectivity, and kinetic properties [61]. Table 2 presents the features of several GECIs [55,56,58,61-80]. Dynamic range is one of the most important features, which is calculated as $I_{\max } /$ $I_{\min }$ where $I_{\max }$ is the maximum fluorescent intensity and $I_{\min }$ is the minimum fluorescent intensity; increasing the $\mathrm{I}_{\max } / \mathrm{I}_{\min }$ value makes calcium signal detection easier. The signal-to-noise ratio is determined by comparing fluorescence signal with background fluorescence noise. Calcium affinity is also a notable feature since GECIs should catch up with calcium dynamics. Although conformational changes and various binding sites can affect calcium affinity [55], ionic strength, ionic composition, and $\mathrm{pH}$ are related to GECI calcium affinity for in vivo conditions [81]. Additionally, ion selectivity is crucial because $\mathrm{Mg}^{2+}$ is the most common divalent cation competing with $\mathrm{Ca}^{2+}$. To remove $\mathrm{Mg}^{2+}$ sensitivity from GECIs, researchers replaced the C-terminal EF-hand motif of troponin $\mathrm{C}$ [82] and made $\mathrm{Mg}^{2+}$-insensitive $\mathrm{Ca}^{2+}$ indicators $[78,82]$. Many kinetic properties, such as the dissociation constant $\left(\mathrm{K}_{\mathrm{d}}\right)$, are supposed to be considered especially when the accurate measurement of $\mathrm{Ca}^{2+}$ transients is required [61].

Considering these GECI properties, GECI development has been diversified because researchers differently prioritize each calcium indicator aspect, such as brightness, response time, and resistance to photobleaching. For instance, researchers can modify higher affinity or faster working GECIs by changing specific motifs or replacing them with suitable ones. The 3D structures of GECIs also allow for developing better GCaMP variant designs [66]. GCaMP3fast-one of the fastest GECIs—was designed by a single point mutation of the first Asp to Ala on each EF-hand $\mathrm{Ca}^{2+}$ binding loop to weaken the $\mathrm{Ca}^{2+}$-CaM-RS20 interaction [67]. GCaMP7, which has sufficient brightness to detect single action potentials [83], has slow kinetics but high $\mathrm{Ca}^{2+}$ affinity [68]. In general, a single action potential induced by calcium transient has a 50 to $60 \mathrm{~ms}$ half-decay time in non-buffered conditions [84]. GCaMP6f has a $71 \mathrm{~ms}$ half-decay time in vitro at $37^{\circ} \mathrm{C}$ [68]. GCaMP3fast-a variant of GCaMP3 - shows a 3 ms half-decay time in vitro [85]. In total, GECIs can be customized to assess calcium properties relating to neural activity.

To avoid spectral overlap with green in fluorescent images, blue and red GECI variants are appropriate options. RCaMP series is a well-known RFP-based GECI that is engineered from mRuby with the GCaMP3 scaffold [86]. jRGECO1a, which is engineered from RCaMP1h and R-GECO1, shows improved sensitivity for neural activity detection [70]. Beyond the red-shifted GECIs, there are some multicolor variants of indicators. For instance, Zhao et al. [65] developed genetically encoded calcium indicators for optical imaging (GECO) by scanning thousands of randomly generated GCaMP3 mutations. GECOs have a large range of variants, including G-GECO, R-GECO, and B-GECO, that represent green, red, and blue fluorescent indicators, respectively. Although these various colored GECOs are useful when researchers want to mark multiple targets or deeper region when using long wavelength of fluorescence, they have limitations including weak intensity and high background when using red fluorescence [87] or tissue photodamage when using blue fluorescent excitation [88].

Table 3. Comparison between two-photon microscopy and microendoscopy

\begin{tabular}{lcc}
\hline \multicolumn{1}{c}{ Optical properties } & $\begin{array}{c}\text { Two-photon } \\
\text { microscopy }\end{array}$ & Microendoscopy \\
\hline Resolution & $\sim 200 \mathrm{~nm}^{\mathrm{a}}$ & $1.5-5.6 \mu \mathrm{m}^{\mathrm{b}}$ \\
Field of view size & $330 \times 350 \mu \mathrm{m}$ & $600 \times 800 \mu \mathrm{m}$ \\
Magnification & $\sim 60 \mathrm{x}^{\mathrm{c}}$ & $2 \mathrm{x}-7 \mathrm{x}^{\mathrm{d}}$ \\
Imaging depth & $70-500 \mu \mathrm{m}^{\mathrm{e}}$ & $50-300 \mu \mathrm{m}^{\mathrm{f}}$ \\
\hline
\end{tabular}

${ }^{a}$ Theoretical value from the equation $\mathrm{d}=0.61 \lambda /$ numerical aperture (NA) [91]. ' $T$ This value depends on the complementary metal-oxide-semiconductor (CMOS) device $[92,93] .{ }^{\text {c}}$ This value depends on the objective lens of microscopy [94], which can be larger than $60 x .{ }^{\mathrm{d}}$ This value depends on the achromatic lens of microendoscopy [102]. 'This value is derived from the cortical surface $[95,96]$. ${ }^{\mathrm{T}}$ This value is derived from the suctioned brain plane and decided by a gradient index (GRIN) lens property [97]. 


\section{IN VIVO GECI IMAGING METHODS}

For stable GECI imaging, retaining strong photostability is of the highest importance. Current GECIs are adjusted to have proper performance in the physical range of calcium ions in an in vivo environment but have different photostabilities. Especially in long-term tracking of cell activities, the photobleaching problem intensifies such that the entire imaging time and the degree of light power should be considered when choosing the proper GECI derivative. GFP derivatives (e.g., GCaMPs) and red fluores-

A

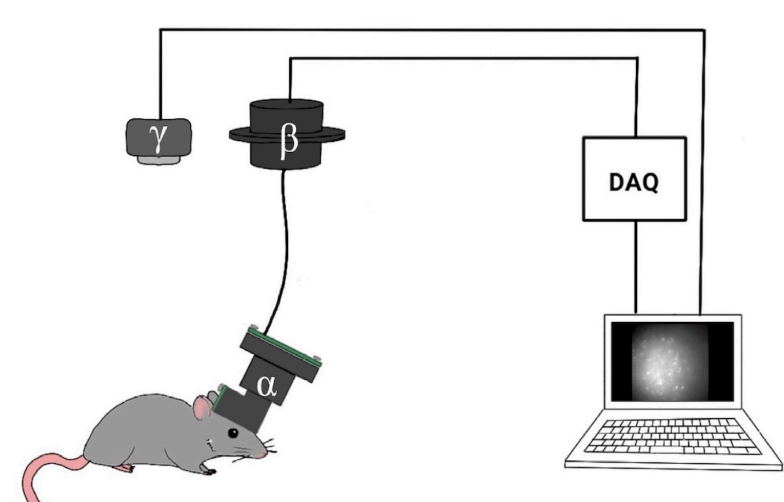

B

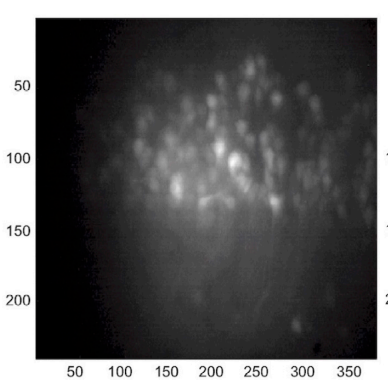

E

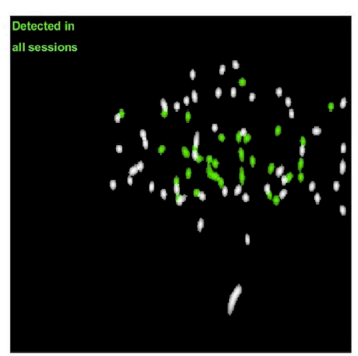

H

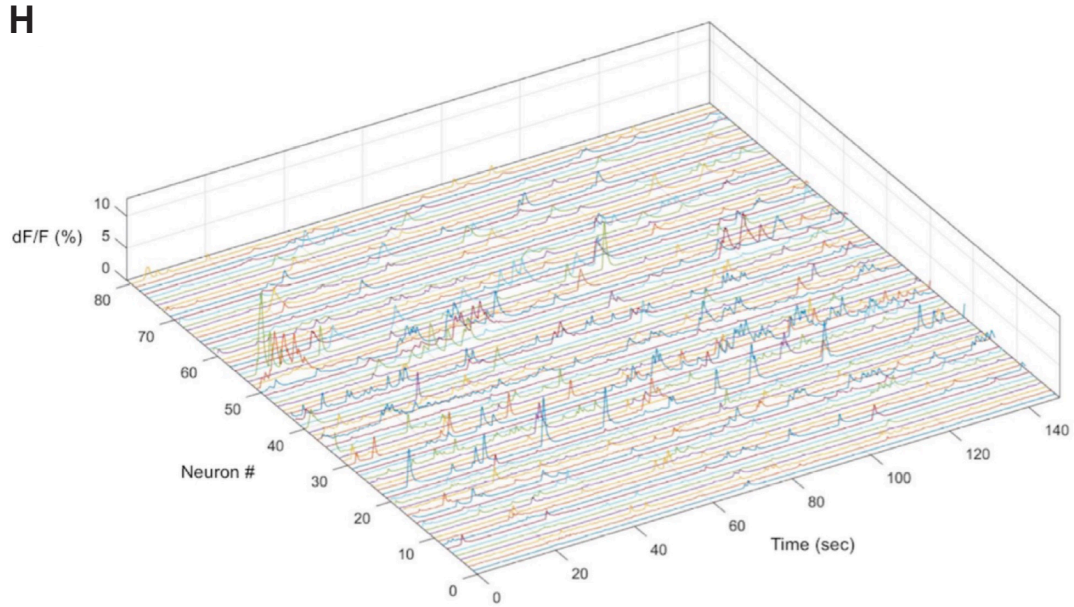

C

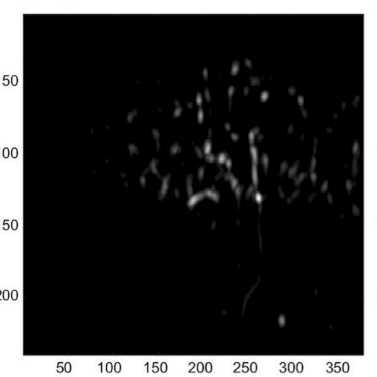

$\mathbf{F}$
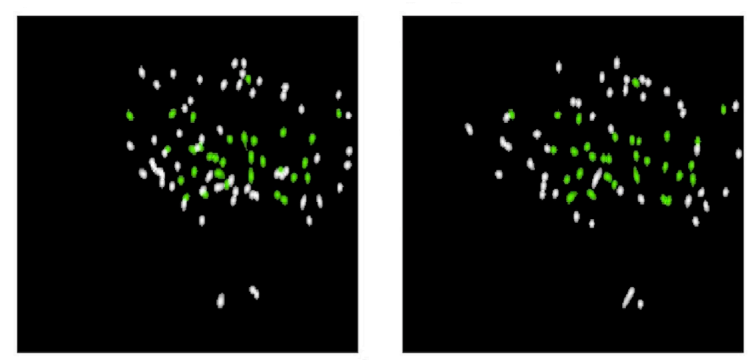

$\begin{array}{lllllll}50 & 100 & 150 & 200 & 250 & 300 & 350\end{array}$

G

D

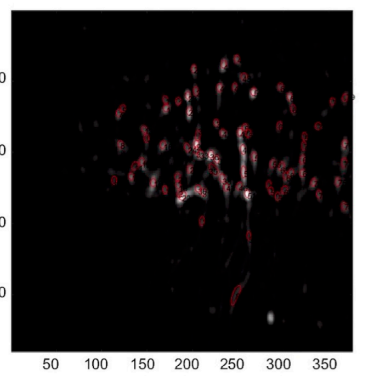
. 
cent protein (RFP) derivatives (e.g., RCaMPs) are often used for a clear distinction. However, GFP variants are more photostable than RFP ones, and the derivatives of other hues, such as yellow or orange, are more vulnerable [89]. Moreover, the time interval between imaging and fluorescent recovery after photobleaching should be considered. For multicolor imaging, the photostability of each fluorescent protein and the types of GECI are worth considering. Regarding GECI types, FRET-based GECIs are based on two emission channels, typically CFP and YFP; accordingly, single FP-based sensors are preferable when choosing GECIs for multi-color imaging. In addition, GECIs are usually expressed stronger in vivo with virus delivery methods compared to using transgenic mouse lines [84].

Generally, in vivo GECI expressing cells are imaged with several methods. Although fiber photometry can image the overall GECI fluorescent signal [90], two-photon microscopy and headmounted microendoscopy can image single cell activation; a comparison of these two GECI imaging types is shown in Table 3 [91-97]. Imaging with two-photon microscopy generally requires fixing the head of an animal in place. Conventional two-photon imaging necessitates undergoing cranial window surgery, which limits the possible imaging region of the cortex [20]. However, there is a new imaging technic combining two-photon microscopy and gradient index (GRIN) lens that enabled two-photon microscopy to overcome the limitation of imaging depth [98-100].

Nevertheless, two-photon microscopy imaging has a commanding advantage that enables high resolution imaging even to the level of dendritic spines [20]. Since only a single focal plane is excited, the background signal is low, less signal overlapping occurs, and photobleaching problem is lessened, all contributing to a clearer and more stable image. With a virtual reality (VR) system, this imaging method can overcome the limitation of behaviors studied, and behavior protocols that involve the movement of animals, as with an animal walking on a ball, can be executed [101]. However, two-photon microscopy has limited imaging depth from a cranial window and requires a noteworthy effort by the animal to habituate head fixation. Overcoming limited penetration depth may become a significant issue for two-photon microscopy.

In contrast, microendoscopy is free from the animal fixation problem because the device is light ( 2 to $3 \mathrm{~g}$ ) and portable enough to study animal behavior (Fig. 3) [102,103]. Previous wired versions needed to be connected to a data acquisition device (DAQ hardware) through a commutator, but, recently, a wireless version with SD card and battery has been developed [101] that is expected to minimize the activity area restriction and the effect on animal task performance. Then again, the wide-field microendoscopy focuses on tracking activity from a neuronal population such that the magnification tends to be smaller for securing a broader view and increasing the number of detected cells; by the same token, as magnification gets smaller and focused on somal calcium imaging, detecting GECI signal at the synaptic level gets more difficult. Nevertheless, the two-photon version of the microendoscopy has recently been developed $[92,104,105]$ and may be a better alternative tool for precise imaging during animal behavior. For vertically-layered areas, such as the neocortex, the image can be attained vertically with a microprism, which converts the vertical image horizontally and relays it to a signal detection device. Microprisms enable recording multi-layer cellular activities [106-108]. Furthermore, Inscopix Inc. developed a new microendoscopy that combines optogenetics tools and calcium imaging devices [109], enabling the simultaneous manipulation of neural circuits and the imaging of calcium signaling. This achievement may be a milestone for neural circuit research.

\section{ANALYSIS OF GECI IMAGES}

Using GECI has enabled researchers to make more sophisticated observations of neuronal activity at the single-cell level. This has led to a few demands for proper analysis tools by researchers to prove their hypotheses. However, GECI analysis at the singlecell level has difficulties because neuronal populations have dynamic properties [110]. Additionally, the huge size (i.e., gigabytes to terabytes) of the video files from GECI images can restrict the analysis that allows researchers to choose the proper options that depend on their research goal, such as time reduction, accuracy, and efficiency. Data processing algorithms and their programming languages also vary across laboratories. Hence, code compatibility is not guaranteed when using several open source codes all at once, potentially leading researchers to improperly choose proper analysis tools. In this section, we will deal with the general processes for analyzing GECI-based images, which can be extended to general fluorescent data analyses.

Regardless of the analytical demands, experimental conditions, and questions, there are three general steps to process GECI data: (1) pre-detection processing, (2) cell detection processing, and (3) post-detection processing. Before running cell detection algorithms, pre-detection processing is essential, which includes motion artifacts deletion, regions of interest (ROI) segmentation, and ROI dF/F0 calculations. In an experiment, the data cannot practically be obtained in a perfectly rigid condition since the camera/ microscope and the target can move or vibrate. Thus, motion artifact deletion is done to align whole GECI images, generally by using a fast Fourier transform (FFT). Additionally, researchers can calculate the maximum cross-correlation between each frame on the field of view consisting of overlapped patches; crosscorrelation results are used to calculate displacement vectors that can be used for aligning all imaged structures. ROI segmentation is a process that discriminates the area of interested elements from that of others. For instance, the signals from neurites can be regarded as noise for some researchers but may be valuable to others. Additionally, since GECIs are expressed in the cytosol and not in the nucleus, some cells can be detected in a ring form or a 
circular form [111]; this should be considered when the soma of neurons is the ROI. Thus, setting the proper threshold to separate ROIs from non-ROIs is essential. As a result, many analysis algorithms allow users to choose those options, such as dendrite on/off, ring/circle, and value of threshold. The dF/F0 calculation is also important because there are basal fluorescent signals from GECIs, and, when imaging GECI signals with general methods, such as microendoscopy or two-photon microscopy, signals from the interested elements can overlap with noise. F0 can be calculated using the average ROI from the user's field selection or with algorithms that estimate it from fluorescence baseline fluctuations.

There are various ways for cell detection processing, from classical principal component analysis and independent component analysis (PCA-ICA) [112] to neural network-based algorithms, such as constrained non-negative matrix factorization (CNMF) and CNMF for endoscopy data (CNMF_E) [113].

PCA-ICA, a well-known analysis method in dimension reduction, is a popular method of many fields. In analyzing GECI signals, PCA performs dimension reduction and noise removal; then, through ICA, researchers can get 2D plots of spatial/temporal skewness of pixels in the spatial filter. Signals can be separated through the skewness level because noise is generally symmetrical. By applying proper clustering techniques, such as k-means clustering, the calcium signal can be extracted [112]. Although the PCA-ICA algorithm is mathematically proved as an efficient classifier that shows prominent data characteristics, general calcium images contain unpredictable elements including dust, motion, and the fluorescent protein expression level. In other words, performing calcium imaging analysis using only PCAICA has potential limits [114], and, perhaps, proper machinelearning algorithms can solve these issues. There are some opensource calcium analysis codes written in various languages, such as MATLAB and Python.

CNMF, an unsupervised learning algorithm like PCA, has a primary pipeline based on three steps. First, input data is converted as a non-negative matrix using column rank normalization. Second, the sample is divided into consensus clusters. Third, each cluster is updated individually [113]. Efficient and accurate extraction of in vivo calcium signals from micro-endoscopic video data with CNMF_E [115] was developed based on the CNMF algorithm; however, CNMF_E was designed to overcome the poor performance originated from insufficiently designed background modeling of CNMF, and, thus, it became more suitable for neuronal cell detection acquired from various imaging methods in addition to two-photon imaging. Subsequently, other deep learning algorithms, such as MIN1PIPE, with Recurrent Neural Networks (RNN) and Long Short-Term Memory (LSTM) [114] are also widely being used for cell detection. MIN1PIPE is used for seed cleansing and detects larger cell numbers than CNMF_ E. MIN1PIPE and CNMF_E-both based on well-constructed algorithms-are widely used in these days. CNMF_E can detect neurons with some true-negatives and false-positives, while MIN1PIPE catches all candidates so false-positive data can be generated. Both codes offer post-filter functions to remove incorrect signals. Additionally, there are some newer codes-as Mosaic (Inscopix), CaImAn [116], and CAVE [117] — that can be chosen or designed depending on the researchers' goals, such as minimizing false positives and maximizing automation, parameter accuracy and performance speed [118].

After cell detection and arrangement, the resulting data should undergo post-detection processing. The characteristics of neuronal calcium signals can be different for various reasons, such as the brain region studied and the fluorescent protein expression level; post-detection processing should be performed with consideration for these characteristics regarding temporal resolution and signal-to-noise ratio of calcium transient. To sort out some baseline noise and some overall sharp noises before making statistical indexes, dF/F0 [119], dynamic programming [120], temporal deconvolution [121], machine learning techniques [122] and overall or windowed high pass filter (HPF) or low pass filter (LPF) [123] could be applied. There are mainly two indexes: peak intensity and peak frequency of each cell. To find a valid peak from the signal, Kitamura et al. [11], used a spike threshold over three sigmas from each neuron's average amplitude. Cai et al. [124] used a dF/F0 threshold over 5\% of the maximum intensity. Researchers can make a spike train from the selected peaks and analyze this processed data as a general spike train. CellReg [125] codes are used for tracking separate GECI video data acquired on multiple days by modeling the distribution of similarities between neighboring cells across daily video data. Fig. 3 shows an anterior cingulate cortex (ACC) brain region image using the UCLA miniscope on a mouse model processed by custom code based on MIN1PIPE [114] and CellReg [125] codes.

\section{CONCLUSION}

In this paper, we reviewed the overall properties of GECIs, from calcium ions/indicators to image analysis. GECIs enable researchers to observe cells with behavior in real time, providing many neural circuit research advantages. The development of GECIs has addressed many imaging aspects (e.g., fluorescent intensity, response time, and photobleaching) and enables the active detection of biological phenomena. As a result, GECIs are being used in various research fields including one- or two-photon imaging or portable imaging, such as microendoscopy. As the analysis methods and imaging techniques have been improved, the overall data quality has as well. Although GECIs have some limitations, GECI imaging is a promising technique for real-time cell activity research. 


\section{ACKNOWLEDGEMENTS}

B.K.K. is supported by the National Honor Scientist Program (NRF-2012R1A3A1050385).

\section{CONFLICTS OF INTEREST}

The authors declare no conflicts of interest.

\section{REFERENCES}

1. Kawashima T, Okuno H, Bito H. A new era for functional labeling of neurons: activity-dependent promoters have come of age. Front Neural Circuits. 2014;8:37.

2. Minatohara K, Akiyoshi M, Okuno H. Role of immediate-early genes in synaptic plasticity and neuronal ensembles underlying the memory trace. Front Mol Neurosci. 2016;8:78.

3. Cho J, Yu NK, Choi JH, Sim SE, Kang SJ, Kwak C, Lee SW, Kim JI, Choi DI, Kim VN, Kaang BK. Multiple repressive mechanisms in the hippocampus during memory formation. Science. 2015;350:8287.

4. Xiu J, Zhang Q, Zhou T, Zhou TT, Chen Y, Hu H. Visualizing an emotional valence map in the limbic forebrain by TAI-FISH. Nat Neurosci. 2014;17:1552-1559.

5. Zhang Q, He Q, Wang J, Fu C, Hu H. Use of TAI-FISH to visualize neural ensembles activated by multiple stimuli. Nat Protoc. 2018;13:118-133.

6. Yokose J, Okubo-Suzuki R, Nomoto M, Ohkawa N, Nishizono H, Suzuki A, Matsuo M, Tsujimura S, Takahashi Y, Nagase M, Watabe AM, Sasahara M, Kato F, Inokuchi K. Overlapping memory trace indispensable for linking, but not recalling, individual memories. Science. 2017;355:398-403.

7. Choi JH, Sim SE, Kim JI, Choi DI, Oh J, Ye S, Lee J, Kim T, Ko HG, Lim CS, Kaang BK. Interregional synaptic maps among engram cells underlie memory formation. Science. 2018;360:430-435.

8. Denny CA, Kheirbek MA, Alba EL, Tanaka KF, Brachman RA, Laughman KB, Tomm NK, Turi GF, Losonczy A, Hen R. Hippocampal memory traces are differentially modulated by experience, time, and adult neurogenesis. Neuron. 2014;83:189-201.

9. Abdou K, Shehata M, Choko K, Nishizono H, Matsuo M, Muramatsu SI, Inokuchi K. Synapse-specific representation of the identity of overlapping memory engrams. Science. 2018;360:1227-1231.

10. Rashid AJ, Yan C, Mercaldo V, Hsiang HL, Park S, Cole CJ, De Cristofaro A, Yu J, Ramakrishnan C, Lee SY, Deisseroth K, Frankland PW, Josselyn SA. Competition between engrams influences fear memory formation and recall. Science. 2016;353:383-387.

11. Kitamura T, Ogawa SK, Roy DS, Okuyama T, Morrissey MD, Smith LM, Redondo RL, Tonegawa S. Engrams and circuits crucial for systems consolidation of a memory. Science. 2017;356:73-78.

12. Roy DS, Kitamura T, Okuyama T, Ogawa SK, Sun C, Obata Y, Yoshiki A, Tonegawa S. Distinct neural circuits for the formation and retrieval of episodic memories. Cell. 2017;170:1000-1012.e19.

13. Allen WE, DeNardo LA, Chen MZ, Liu CD, Loh KM, Fenno LE,
Ramakrishnan C, Deisseroth K, Luo L. Thirst-associated preoptic neurons encode an aversive motivational drive. Science. 2017; 357:1149-1155.

14. Kitamura T, Pignatelli M, Suh J, Kohara K, Yoshiki A, Abe K, Tonegawa S. Island cells control temporal association memory. Science. 2014;343:896-901.

15. Ye X, Kapeller-Libermann D, Travaglia A, Inda MC, Alberini CM. Direct dorsal hippocampal-prelimbic cortex connections strengthen fear memories. Nat Neurosci. 2017;20:52-61.

16. Lu J, Tucciarone J, Padilla-Coreano N, He M, Gordon JA, Huang ZJ. Selective inhibitory control of pyramidal neuron ensembles and cortical subnetworks by chandelier cells. Nat Neurosci. 2017; 20:1377-1383.

17. Inoue KI, Takada M, Matsumoto M. Neuronal and behavioural modulations by pathway-selective optogenetic stimulation of the primate oculomotor system. Nat Commun. 2015;6:8378.

18. Kim S, Yu NK, Shim KW, Kim JI, Kim H, Han DH, Choi JE, Lee SW, Choi DI, Kim MW, Lee DS, Lee K, Galjart N, Lee YS, Lee JH, Kaang BK. Remote memory and cortical synaptic plasticity require neuronal CCCTC-Binding Factor (CTCF). J Neurosci. 2018;38:5042-5052.

19. Kang SJ, Kim S, Lee J, Kwak C, Lee K, Zhuo M, Kaang BK. Inhibition of anterior cingulate cortex excitatory neuronal activity induces conditioned place preference in a mouse model of chronic inflammatory pain. Korean J Physiol Pharmacol. 2017;21:487-493.

20. El-Boustani S, Ip JPK, Breton-Provencher V, Knott GW, Okuno $\mathrm{H}$, Bito H, Sur M. Locally coordinated synaptic plasticity of visual cortex neurons in vivo. Science. 2018;360:1349-1354.

21. Markowitz JE, Gillis WF, Beron CC, Neufeld SQ, Robertson K, Bhagat ND, Peterson RE, Peterson E, Hyun M, Linderman SW, Sabatini BL, Datta SR. The striatum organizes 3D behavior via moment-to-moment action selection. Cell. 2018;174:44-58.e17.

22. Dimitrov D, He Y, Mutoh H, Baker BJ, Cohen L, Akemann W, Knöpfel T. Engineering and characterization of an enhanced fluorescent protein voltage sensor. PLoS One. 2007;2:e440.

23. Siegel MS, Isacoff EY. A genetically encoded optical probe of membrane voltage. Neuron. 1997;19:735-741.

24. Ataka K, Pieribone VA. A genetically targetable fluorescent probe of channel gating with rapid kinetics. Biophys J. 2002;82(1 Pt 1):509-516.

25. Kang BE, Baker BJ. Pado, a fluorescent protein with proton channel activity can optically monitor membrane potential, intracellular pH, and map gap junctions. Sci Rep. 2016;6:23865.

26. Jin L, Han Z, Platisa J, Wooltorton JR, Cohen LB, Pieribone VA. Single action potentials and subthreshold electrical events imaged in neurons with a fluorescent protein voltage probe. Neuron. 2012;75:779-785.

27. Kannan M, Vasan G, Pieribone VA. Optimizing strategies for developing genetically encoded voltage indicators. Front Cell Neurosci. 2019;13:53.

28. Baker BJ, Mutoh H, Dimitrov D, Akemann W, Perron A, Iwamoto Y, Jin L, Cohen LB, Isacoff EY, Pieribone VA, Hughes T, Knöpfel T. Genetically encoded fluorescent sensors of membrane potential. Brain Cell Biol. 2008;36:53-67.

29. Baker BJ, Lee H, Pieribone VA, Cohen LB, Isacoff EY, Knopfel T, Kosmidis EK. Three fluorescent protein voltage sensors exhibit low plasma membrane expression in mammalian cells. J Neurosci 
Methods. 2007;161:32-38.

30. Yang HH, St-Pierre F, Sun X, Ding X, Lin MZ, Clandinin TR. Subcellular imaging of voltage and calcium signals reveals neural processing in vivo. Cell. 2016;166:245-257.

31. Platisa J, Vasan G, Yang A, Pieribone VA. Directed evolution of key residues in fluorescent protein inverses the polarity of voltage sensitivity in the genetically encoded indicator ArcLight. ACS Chem Neurosci. 2017;8:513-523.

32. Iamshanova O, Mariot P, Lehen'kyi V, Prevarskaya N. Comparison of fluorescence probes for intracellular sodium imaging in prostate cancer cell lines. Eur Biophys J. 2016;45:765-777.

33. Kaihara A, Sunami A, Kurokawa J, Furukawa T. A genetically encoded bioluminescent indicator for the sodium channel activity in living cells. J Am Chem Soc. 2009;131:4188-4189.

34. Kandel ER, Schwartz JH, Jessell TM. Principles of neural science. 4th ed. New York: McGraw-Hill; 2000.

35. Zerangue N, Kavanaugh MP. Flux coupling in a neuronal glutamate transporter. Nature. 1996;383:634-637.

36. Grienberger C, Konnerth A. Imaging calcium in neurons. Neuron. 2012;73:862-885.

37. Inoue M, Takeuchi A, Horigane S, Ohkura M, Gengyo-Ando K, Fujii H, Kamijo S, Takemoto-Kimura S, Kano M, Nakai J, Kitamura K, Bito H. Rational design of a high-affinity, fast, red calcium indicator R-CaMP2. Nat Methods. 2015;12:64-70.

38. Kamijo S, Ishii Y, Horigane SI, Suzuki K, Ohkura M, Nakai J, Fujii $\mathrm{H}$, Takemoto-Kimura S, Bito $\mathrm{H}$. A critical neurodevelopmental role for L-type voltage-gated calcium channels in neurite extension and radial migration. JNeurosci. 2018;38:5551-5566.

39. Berridge MJ, Bootman MD, Roderick HL. Calcium signalling: dynamics, homeostasis and remodelling. Nat Rev Mol Cell Biol. 2003;4:517-529.

40. Berridge MJ, Lipp P, Bootman MD. The versatility and universality of calcium signalling. Nat Rev Mol Cell Biol. 2000;1:11-21.

41. Atlas D. The voltage-gated calcium channel functions as the molecular switch of synaptic transmission. Annu Rev Biochem. 2013;82:607-635.

42. Kim HL, Chang YJ, Lee SM, Hong YS. Genomic structure of the regulatory region of the voltage-gated calcium channel alpha 1D. Exp Mol Med. 1998;30:246-251.

43. Niswender CM, Conn PJ. Metabotropic glutamate receptors: physiology, pharmacology, and disease. Annu Rev Pharmacol Toxicol. 2010;50:295-322.

44. Prakriya M, Lewis RS. Store-operated calcium channels. Physiol Rev. 2015;95:1383-1436.

45. Bagur R, Hajnóczky G. Intracellular $\mathrm{Ca}^{2+}$ sensing: its role in calcium homeostasis and signaling. Mol Cell. 2017;66:780-788.

46. Zahradník I, Györke S, Zahradníková A. Calcium activation of ryanodine receptor channels--reconciling RyR gating models with tetrameric channel structure. J Gen Physiol. 2005;126:515-527.

47. Kania E, Roest G, Vervliet T, Parys JB, Bultynck G. $\mathrm{IP}_{3}$ receptormediated calcium signaling and its role in autophagy in cancer. Front Oncol. 2017;7:140.

48. Glancy B, Balaban RS. Role of mitochondrial $\mathrm{Ca}^{2+}$ in the regulation of cellular energetics. Biochemistry. 2012;51:2959-2973.

49. Schwaller B. Cytosolic $\mathrm{Ca}^{2+}$ buffers. Cold Spring Harb Perspect Biol. 2010;2:a004051.

50. Larkum ME, Watanabe S, Nakamura T, Lasser-Ross N, Ross WN.
Synaptically activated $\mathrm{Ca}^{2+}$ waves in layer $2 / 3$ and layer 5 rat neocortical pyramidal neurons. J Physiol. 2003;549(Pt 2):471-488.

51. Reddish FN, Miller CL, Gorkhali R, Yang JJ. Calcium dynamics mediated by the endoplasmic/sarcoplasmic reticulum and related diseases. Int J Mol Sci. 2017;18:E1024.

52. Shimomura O, Johnson FH, Saiga Y. Extraction, purification and properties of aequorin, a bioluminescent protein from the luminous hydromedusan, Aequorea. J Cell Comp Physiol. 1962;59:223239.

53. Brown JE, Cohen LB, De Weer P, Pinto LH, Ross WN, Salzberg $\mathrm{BM}$. Rapid changes in intracellular free calcium concentration. Detection by metallochromic indicator dyes in squid giant axon. Biophys J. 1975;15:1155-1160.

54. Paredes RM, Etzler JC, Watts LT, Zheng W, Lechleiter JD. Chemical calcium indicators. Methods. 2008;46:143-151.

55. Miyawaki A, Llopis J, Heim R, McCaffery JM, Adams JA, Ikura M, Tsien RY. Fluorescent indicators for $\mathrm{Ca}^{2+}$ based on green fluorescent proteins and calmodulin. Nature. 1997;388:882-887.

56. Tallini YN, Ohkura M, Choi BR, Ji G, Imoto K, Doran R, Lee J, Plan P, Wilson J, Xin HB, Sanbe A, Gulick J, Mathai J, Robbins J, Salama G, Nakai J, Kotlikoff MI. Imaging cellular signals in the heart in vivo: cardiac expression of the high-signal $\mathrm{Ca}^{2+}$ indicator GCaMP2. Proc Natl Acad Sci U S A. 2006;103:4753-4758.

57. Akerboom J, Rivera JD, Guilbe MM, Malavé EC, Hernandez HH, Tian L, Hires SA, Marvin JS, Looger LL, Schreiter ER. Crystal structures of the GCaMP calcium sensor reveal the mechanism of fluorescence signal change and aid rational design. J Biol Chem. 2009;284:6455-6464.

58. Tang S, Wong HC, Wang ZM, Huang Y, Zou J, Zhuo Y, Pennati A, Gadda G, Delbono O, Yang JJ. Design and application of a class of sensors to monitor $\mathrm{Ca}^{2+}$ dynamics in high $\mathrm{Ca}^{2+}$ concentration cellular compartments. Proc Natl Acad Sci U S A. 2011;108:16265-16270.

59. Jares-Erijman EA, Jovin TM. FRET imaging. Nat Biotechnol. 2003;21:1387-1395.

60. Nakamura T, Barbara JG, Nakamura K, Ross WN. Synergistic release of $\mathrm{Ca}^{2+}$ from IP3-sensitive stores evoked by synaptic activation of mGluRs paired with backpropagating action potentials. Neuron. 1999;24:727-737.

61. Pérez Koldenkova V, Nagai T. Genetically encoded $\mathrm{Ca}^{2+}$ indicators: properties and evaluation. Biochim Biophys Acta. 2013;1833:17871797.

62. Nakai J, Ohkura M, Imoto K. A high signal-to-noise $\mathrm{Ca}^{2+}$ probe composed of a single green fluorescent protein. Nat Biotechnol. 2001;19:137-141.

63. Reiff DF, Ihring A, Guerrero G, Isacoff EY, Joesch M, Nakai J, Borst A. In vivo performance of genetically encoded indicators of neural activity in flies. J Neurosci. 2005;25:4766-4778.

64. Ohkura M, Matsuzaki M, Kasai H, Imoto K, Nakai J. Genetically encoded bright $\mathrm{Ca}^{2+}$ probe applicable for dynamic $\mathrm{Ca}^{2+}$ imaging of dendritic spines. Anal Chem. 2005;77:5861-5869.

65. Zhao Y, Araki S, Wu J, Teramoto T, Chang YF, Nakano M, Abdelfattah AS, Fujiwara M, Ishihara T, Nagai T, Campbell RE. An expanded palette of genetically encoded $\mathrm{Ca}^{2+}$ indicators. Science. 2011;333:1888-1891.

66. Akerboom J, Chen TW, Wardill TJ, Tian L, Marvin JS, Mutlu S, Calderón NC, Esposti F, Borghuis BG, Sun XR, Gordus A, Orger MB, Portugues R, Engert F, Macklin JJ, Filosa A, Aggarwal A, Kerr 
RA, Takagi R, Kracun S, et al. Optimization of a GCaMP calcium indicator for neural activity imaging. J Neurosci. 2012;32:1381913840.

67. Helassa N, Zhang XH, Conte I, Scaringi J, Esposito E, Bradley J, Carter T, Ogden D, Morad M, Török K. Fast-response calmodulinbased fluorescent indicators reveal rapid intracellular calcium dynamics. Sci Rep. 2015;5:15978.

68. Chen TW, Wardill TJ, Sun Y, Pulver SR, Renninger SL, Baohan A, Schreiter ER, Kerr RA, Orger MB, Jayaraman V, Looger LL, Svoboda K, Kim DS. Ultrasensitive fluorescent proteins for imaging neuronal activity. Nature. 2013;499:295-300.

69. Barnett LM, Hughes TE, Drobizhev M. Deciphering the molecular mechanism responsible for GCaMP6m's $\mathrm{Ca}^{2+}$-dependent change in fluorescence. PLoS One. 2017;12:e0170934.

70. Dana H, Mohar B, Sun Y, Narayan S, Gordus A, Hasseman JP, Tsegaye G, Holt GT, Hu A, Walpita D, Patel R, Macklin JJ, Bargmann CI, Ahrens MB, Schreiter ER, Jayaraman V, Looger LL, Svoboda K, Kim DS. Sensitive red protein calcium indicators for imaging neural activity. Elife. 2016;5:e12727.

71. Nagai T, Sawano A, Park ES, Miyawaki A. Circularly permuted green fluorescent proteins engineered to sense $\mathrm{Ca}^{2+}$. Proc Natl Acad Sci U S A. 2001;98:3197-3202.

72. Baird GS, Zacharias DA, Tsien RY. Circular permutation and receptor insertion within green fluorescent proteins. Proc Natl Acad Sci U S A. 1999;96:11241-11246.

73. Griesbeck O, Baird GS, Campbell RE, Zacharias DA, Tsien RY. Reducing the environmental sensitivity of yellow fluorescent protein. Mechanism and applications. J Biol Chem. 2001;276:29188-29194.

74. Miyawaki A, Griesbeck O, Heim R, Tsien RY. Dynamic and quantitative $\mathrm{Ca}^{2+}$ measurements using improved cameleons. Proc Natl Acad Sci U S A. 1999;96:2135-2140.

75. Nagai T, Yamada S, Tominaga T, Ichikawa M, Miyawaki A. Expanded dynamic range of fluorescent indicators for $\mathrm{Ca}^{2+}$ by circularly permuted yellow fluorescent proteins. Proc Natl Acad Sci U S A. 2004;101:10554-10559.

76. Horikawa K, Yamada Y, Matsuda T, Kobayashi K, Hashimoto M, Matsu-ura T, Miyawaki A, Michikawa T, Mikoshiba K, Nagai T. Spontaneous network activity visualized by ultrasensitive $\mathrm{Ca}^{2+}$ indicators, yellow Cameleon-Nano. Nat Methods. 2010;7:729-732.

77. Palmer AE, Giacomello M, Kortemme T, Hires SA, Lev-Ram V, Baker D, Tsien RY. $\mathrm{Ca}^{2+}$ indicators based on computationally redesigned calmodulin-peptide pairs. Chem Biol. 2006;13:521-530.

78. Heim N, Griesbeck O. Genetically encoded indicators of cellular calcium dynamics based on troponin $\mathrm{C}$ and green fluorescent protein. J Biol Chem. 2004;279:14280-14286.

79. Mank M, Reiff DF, Heim N, Friedrich MW, Borst A, Griesbeck O. A FRET-based calcium biosensor with fast signal kinetics and high fluorescence change. Biophys J. 2006;90:1790-1796.

80. Waldeck-Weiermair M, Alam MR, Khan MJ, Deak AT, Vishnu N, Karsten F, Imamura H, Graier WF, Malli R. Spatiotemporal correlations between cytosolic and mitochondrial $\mathrm{Ca}^{2+}$ signals using a novel red-shifted mitochondrial targeted cameleon. PLoS One. 2012;7:e45917.

81. Hires SA, Tian L, Looger LL. Reporting neural activity with genetically encoded calcium indicators. Brain Cell Biol. 2008;36:69-86.

82. Mank M, Griesbeck O. Genetically encoded calcium indicators. Chem Rev. 2008:108:1550-1564.
83. Muto A, Ohkura M, Abe G, Nakai J, Kawakami K. Real-time visualization of neuronal activity during perception. Curr Biol. 2013;23:307-311.

84. Lin MZ, Schnitzer MJ. Genetically encoded indicators of neuronal activity. Nat Neurosci. 2016;19:1142-1153.

85. Helassa N, Podor B, Fine A, Török K. Design and mechanistic insight into ultrafast calcium indicators for monitoring intracellular calcium dynamics. Sci Rep. 2016;6:38276.

86. Akerboom J, Carreras Calderón N, Tian L, Wabnig S, Prigge M, Tolö J, Gordus A, Orger MB, Severi KE, Macklin JJ, Patel R, Pulver SR, Wardill TJ, Fischer E, Schüler C, Chen TW, Sarkisyan KS, Marvin JS, Bargmann CI, Kim DS, et al. Genetically encoded calcium indicators for multi-color neural activity imaging and combination with optogenetics. Front Mol Neurosci. 2013;6:2.

87. Higuchi-Sanabria R, Garcia EJ, Tomoiaga D, Munteanu EL, Feinstein P, Pon LA. Characterization of fluorescent proteins for threeand four-color live-cell imaging in S. cerevisiae. PLoS One. 2016; 11:e0146120.

88. Wäldchen S, Lehmann J, Klein T, van de Linde S, Sauer M. Lightinduced cell damage in live-cell super-resolution microscopy. Sci Rep. 2015;5:15348.

89. Shaner NC, Steinbach PA, Tsien RY. A guide to choosing fluorescent proteins. Nat Methods. 2005;2:905-909.

90. Adamsky A, Kol A, Kreisel T, Doron A, Ozeri-Engelhard N, Melcer T, Refaeli R, Horn H, Regev L, Groysman M, London M, Goshen I. Astrocytic activation generates de novo neuronal potentiation and memory enhancement. Cell. 2018;174:59-71.e14.

91. Pawley JB. Handbook of biological confocal microscopy. 3rd ed. Boston: Springer US; 2006.

92. Zong W, Wu R, Li M, Hu Y, Li Y, Li J, Rong H, Wu H, Xu Y, Lu Y, Jia H, Fan M, Zhou Z, Zhang Y, Wang A, Chen L, Cheng H. Fast high-resolution miniature two-photon microscopy for brain imaging in freely behaving mice. Nat Methods. 2017;14:713-719.

93. Zhang L, Liang B, Barbera G, Hawes S, Zhang Y, Stump K, Baum I, Yang Y, Li Y, Lin DT. Miniscope GRIN lens system for calcium imaging of neuronal activity from deep brain structures in behaving animals. Curr Protoc Neurosci. 2019;86:e56.

94. Doi A, Oketani R, Nawa Y, Fujita K. High-resolution imaging in two-photon excitation microscopy using in situ estimations of the point spread function. Biomed Opt Express. 2017;9:202-213.

95. Kobat D, Horton NG, Xu C. In vivo two-photon microscopy to 1.6mm depth in mouse cortex. J Biomed Opt. 2011;16:106014.

96. Ntziachristos V. Going deeper than microscopy: the optical imaging frontier in biology. Nat Methods. 2010;7:603-614.

97. UCLA Miniscope. Overview of system components [Internet]. UCLA Miniscope [cited 2018 Nov 11]. Available from: http://miniscope.org/index.php/Overview_of_System_Components.

98. Resendez SL, Jennings JH, Ung RL, Namboodiri VM, Zhou ZC, Otis JM, Nomura H, McHenry JA, Kosyk O, Stuber GD. Visualization of cortical, subcortical and deep brain neural circuit dynamics during naturalistic mammalian behavior with head-mounted microscopes and chronically implanted lenses. Nat Protoc. 2016;11: 566-597.

99. Yan W, Peng X, Lin D, Wang Q, Gao J, Luo T, Zhou J, Ye T, Qu J, Niu H. Fluorescence microendoscopy imaging based on GRIN lenses with one- and two-photon excitation modes. Front Optoelectron. 2015;8:177-182. 
100. Yan W, Peng X, Lin D, Wang Q, Gao J, Zhou J, Ye T, Qu J, Niu H. Two-photon excited fluorescence microendoscopic imaging using a GRIN lens. In: König K, editor. Multiphoton microscopy in the biomedical sciences XV. Bellingham: SPIE; 2015.

101. Shuman T, Aharoni D, Cai DJ, Lee CR, Chavlis S, Taxidis J, Flores SE, Cheng K, Javaherian M, Kaba CC, Shtrahman M, Bakhurin KI, Masmanidis S, Khakh BS, Poirazi P, Silva AJ, Golshani P. Breakdown of spatial coding and neural synchronization in epilepsy. bioRxiv. 2018. doi: 10.1101/358580.

102. Ghosh KK, Burns LD, Cocker ED, Nimmerjahn A, Ziv Y, Gamal AE, Schnitzer MJ. Miniaturized integration of a fluorescence microscope. Nat Methods. 2011;8:871-878.

103. Evans DA, Stempel AV, Vale R, Ruehle S, Lefler Y, Branco T. A synaptic threshold mechanism for computing escape decisions. Nature. 2018;558:590-594.

104. Helmchen F, Fee MS, Tank DW, Denk W. A miniature headmounted two-photon microscope. high-resolution brain imaging in freely moving animals. Neuron. 2001;31:903-912.

105. Silva AJ. Miniaturized two-photon microscope: seeing clearer and deeper into the brain. Light Sci Appl. 2017;6:e17104.

106. Koizumi K, Inoue M, Chowdhury S, Bito H, Yamanaka A, Ishizuka T, Yawo H. Functional emergence of a column-like architecture in layer 5 of mouse somatosensory cortex in vivo. J Physiol Sci. 2019;69:65-77.

107. Andermann ML, Gilfoy NB, Goldey GJ, Sachdev RN, Wölfel M, McCormick DA, Reid RC, Levene MJ. Chronic cellular imaging of entire cortical columns in awake mice using microprisms. Neuron. 2013;80:900-913.

108. Chia TH, Levene MJ. Microprisms for in vivo multilayer cortical imaging. J Neurophysiol. 2009;102:1310-1314.

109. Stamatakis AM, Schachter MJ, Gulati S, Zitelli KT, Malanowski S, Tajik A, Fritz C, Trulson M, Otte SL. Simultaneous optogenetics and cellular resolution calcium imaging during active behavior using a miniaturized microscope. Front Neurosci. 2018;12:496.

110. Briggman KL, Kristan WB. Multifunctional pattern-generating circuits. Annu Rev Neurosci. 2008;31:271-294.

111. Romano SA, Pérez-Schuster V, Jouary A, Boulanger-Weill J, Candeo A, Pietri T, Sumbre G. An integrated calcium imaging processing toolbox for the analysis of neuronal population dynamics. PLoS Comput Biol. 2017;13:e1005526.

112. Mukamel EA, Nimmerjahn A, Schnitzer MJ. Automated analysis of cellular signals from large-scale calcium imaging data. Neuron. 2009;63:747-760.

113. Pnevmatikakis EA, Soudry D, Gao Y, Machado TA, Merel J, Pfau D, Reardon T, Mu Y, Lacefield C, Yang W, Ahrens M, Bruno R, Jes- sell TM, Peterka DS, Yuste R, Paninski L. Simultaneous denoising, deconvolution, and demixing of calcium imaging data. Neuron. 2016;89:285-299.

114. Lu J, Li C, Singh-Alvarado J, Zhou ZC, Fröhlich F, Mooney R, Wang F. MIN1PIPE: a miniscope 1-photon-based calcium imaging signal extraction pipeline. Cell Rep. 2018;23:3673-3684.

115. Zhou P, Resendez SL, Rodriguez-Romaguera J, Jimenez JC, Neufeld SQ, Giovannucci A, Friedrich J, Pnevmatikakis EA, Stuber GD, Hen R, Kheirbek MA, Sabatini BL, Kass RE, Paninski L. Efficient and accurate extraction of in vivo calcium signals from microendoscopic video data. Elife. 2018;7:e28728.

116. Giovannucci A, Friedrich J, Gunn P, Kalfon J, Brown BL, Koay SA, Taxidis J, Najafi F, Gauthier JL, Zhou P, Khakh BS, Tank DW, Chklovskii DB, Pnevmatikakis EA. CaImAn an open source tool for scalable calcium imaging data analysis. Elife. 2019;8:e38173.

117. Tegtmeier J, Brosch M, Janitzky K, Heinze HJ, Ohl FW, Lippert MT. CAVE: an open-source tool for combined analysis of headmounted calcium imaging and behavior in MATLAB. Front Neurosci. 2018;12:958.

118. Friedrich J, Zhou P, Paninski L. Fast online deconvolution of calcium imaging data. PLoS Comput Biol. 2017;13:e1005423.

119. Mao BQ, Hamzei-Sichani F, Aronov D, Froemke RC, Yuste R. Dynamics of spontaneous activity in neocortical slices. Neuron. 2001;32:883-898.

120. Greenberg DS, Houweling AR, Kerr JN. Population imaging of ongoing neuronal activity in the visual cortex of awake rats. Nat Neurosci. 2008;11:749-751.

121. Holekamp TF, Turaga D, Holy TE. Fast three-dimensional fluorescence imaging of activity in neural populations by objectivecoupled planar illumination microscopy. Neuron. 2008;57:661-672.

122. Sasaki T, Takahashi N, Matsuki N, Ikegaya Y. Fast and accurate detection of action potentials from somatic calcium fluctuations. $J$ Neurophysiol. 2008;100:1668-1676.

123. Balkenius A, Johansson AJ, Balkenius C. Comparing analysis methods in functional calcium imaging of the insect brain. PLoS One. 2015;10:e0129614.

124. Cai DJ, Aharoni D, Shuman T, Shobe J, Biane J, Song W, Wei B, Veshkini M, La-Vu M, Lou J, Flores SE, Kim I, Sano Y, Zhou M, Baumgaertel K, Lavi A, Kamata M, Tuszynski M, Mayford M, Golshani $\mathrm{P}$, et al. A shared neural ensemble links distinct contextual memories encoded close in time. Nature. 2016;534:115-118.

125. Sheintuch L, Rubin A, Brande-Eilat N, Geva N, Sadeh N, Pinchasof $\mathrm{O}$, Ziv Y. Tracking the same neurons across multiple days in $\mathrm{Ca}^{2+}$ imaging data. Cell Rep. 2017;21:1102-1115. 